\begin{tabular}{ll} 
Kastamonu Eğitim Dergisi & \\
& $\begin{array}{l}\text { Kastamonu Education Journal } \\
\text { Mart 2019 Cilt:27 Sayl:2 } \\
\text { kefdergi.kastamonu.edu.tr }\end{array}$ \\
\hline
\end{tabular}

\title{
Çoklu Ortam Öğrenme Materyalinin Akademik Başarıya ve Kalıcılık Düzeyine Etkisi
}

\section{The Effect of Multimedia Learning Material on Academic Performance and Retention}

\section{Öz}

\author{
Eyup YÜNKÜL ${ }^{1}$
}

Araştırmanın amacı Çoklu Ortam Öğrenme Bilişsel Teorisine göre hazırlanan yazılımın öğrenci başarısına ve kalıcılık düzeyine etkisini incelemektir. Bu çalışma, eğitim fakültelerinin lisans programlarında yer alan Öğretim illke ve Yöntemleri dersinde, çoklu ortam yazııımıyla (ÇOY) yapılan öğretimin öğrencilerin başarılarına ve kalıcılığa olan etkisini araştıran yarı deneysel bir çalışmadır. Çalışmada, deney grubunda( $N=20)$ çOY ile ve kontrol grubunda( $N=21)$ ise geleneksel yöntemle (yüzyüze) öğretim yapıımıştır. Çalışmanın sonunda grupların ders başarıları öntest, sontest ve kalıcılık testi ile karşılaştrıımıştır. Elde edilen bulguların analizi sonucunda deney grubu öğrenenlerinin kontrol grubu öğrenenlerine göre sontest ve kalıcılık testi puanlarının daha başarılı olduğu görülmüştür. Bu sonuca bağlı olarak bunun gibi kuramsal temellere dayanan çalışmaların yaygınlaştrılması önerilmiştir.

Anahtar Kelimeler: Başarı, çoklu ortam, kalıcılık

\section{Abstract}

The purpose of the study is to investigate the effect of the software designed according to the multimedia learning cognitive theory on students' academic performances. This is a semi experimental study which investigates the effect of a multimedia software (MS) on academic performance and retention on the level of higher education, in the course of Teaching Principles and Methods in an Education Faculty in Turkey. In the experiment group ( $N=20$ ) MS was used, and in the control group ( $\mathrm{N}=21$ ) traditional methods were used. And then students' performances in both groups were compared in the course of Teaching Principles and Methods. According to the results. it was seen that test group learners were more successful in posttest and persistence test scores than control group learners. In this context, it has been proposed to disseminate studies based on theoretical foundations.

Keywords: Academic performance, multimedia, retention 


\section{Extended Summary}

Purpose :The purpose of the study is to investigate the effect of the software designed according to the multimedia learning cognitive theory on students' academic performances. This is a semi experimental study which investigates the effect of a multimedia software (MS) on academic performance and retention on the level of higher education, in the course of Teaching Principles and Methods in an Education Faculty in Turkey. In the experimental group( $\mathrm{N}=20) \mathrm{MS}$ was used, and in the control group( $\mathrm{N}=21)$ traditional methods were used. And then students' performances in both groups were compared in the course of Teaching Principles and Methods.

Method: A quasi-experimental design was used in the study. Participants of the study were the 2nd grade students enrolled to the Teaching Principles and Methods course in the department of Computer Education and Instructional Technologies. An academic achievement test which was developed by the researcher was used to evaluate the performances of students before and after the experimental process.

A two-way mixed ANOVA test was used to evaluate the changes on the students' performances in pre-test, post-test and retention test in both experiment and control groups. A two-way mixed ANOVA test is used to test the effect of experimental process in independent measures or repeated measures in different groups in two factor mixed design (split plot) studies (Büyüköztürk, 2011).

Findings :According to the findings of the study, in both groups students' performance scores were increased in post-test with regard to the pre-test. Therefore both MS and traditional methods were effective in teaching. However it was found that students' performance scores in experimental group were higher than students' performance scores in control group. It was found that in consequence of the experimental process students' performance scores of post-test and retention test in experimental group was significantly different from those in control group in favor of experimental group.

To determine the source of the difference, in other words to compare the differences in two variables (determining which test scores hd differences), Bonferroni test was used. As a result these were significant difference between control and experimental groups in regard to the pre-test to post-test, pre-test to retention test and post test to retention test $(p<.01)$.

In addition an ANCOVA analysis was performed to verify the effect of experimental process by considering the variable, the students' scores in the course of Introduction to Educational Sciences, as a control variable. All of the students took the Introduction to Educational Sciences course taught with traditional methods. Similarly, it was found that there were differences in students' performance scores of pre-test, post-test and retention test in favor of experimental group even by controlling the variable of students' scores in the course of Introduction to Educational Sciences.

Besides, with same the technique the effect of the experimental process was verified with ANCOVA test with controlling students' CGPA (cumulative grade point average) scores. Similarly, it was found that there were differences in students' performance scores of pre-test, post-test and retention test in favor of experimental group even by controlling the variable of students' CGPA scores.

In both experimental and control groups, students' performance scores in retention test were decreased a little in regard to post-test scores. However, the decrease in the control group students' performance scores was higher. It was found that there was not any statistically significant difference between the post-test scores and retention scores of students in experimental group. However, it was found that there was a statistically significant difference between the post-test scores and retention scores of students in control group. According to this findings, It was determined that students' retention level in experimental group was higher than those in control group. In other words, Students who studied the course with MS were more successful than students who took the course with traditional methods in regard of retention.

According to the results, the following suggestions can be made:

- Instructional software could be developed for other courses. Thus, the effect of these software on academic success could be investigated.

- Theoretical foundations such as CTML(Cognitive Theory of Multimedia Learning) should be considered, when preparing instructional software like MS.

- Studies could be conducted in which each of the Multimedia Learning principles is investigated separately. 


\section{Giriş}

Eğitimde Bilgi ve iletişim teknolojilerinin (BiT) kullanılması, öğrenme ortamında yeni firsatlar(çevrimiçi öğrenme, çevrimiçi işbirlikli öğrenme, çoklu ortam öğrenme vb.) sunabilecek çeşitli araçlar sağlayarak, öğrencilerin bireysel ihtiyaçlarına ve özelliklerine göre eğitim sürecini şekillendirmeye yardımcı olmaktadır (Hussain, 2018; Taşkesen ve Yılmaz, 2018; Tezci, 2016). Öğrenme ortamında öğrenen özelliklerinin dikkate alınması, kalıcı ve etkili öğrenmeler gerçekleştirebilmek adına büyük önem taşımaktadır (Yılmaz ve Özgür Dinçol, 2012). Öğrenme, insanın duyu organları yoluyla gelen uyarıcıları algılaması, yorumlaması ve anlamlandırması olarak düşünüldüğünde; öğrenme ortamı ve öğretim etkinlikleri ne kadar çok duyu organına hitap ederse, öğrenme de o kadar iyi ve kalıcı olmakta ve dolayısıyla unutma da geç gerçekleşmektedir (Nalçacı ve Ercoşkun, 2005; Saban, 2008; Semerci, 2006). Öğrenme ortamları, BiT'in sunduğu öğretim teknolojileri kullanılarak tasarlandığında bireylerin daha fazla duyusuna hitap eden çevreler haline gelebilmektedir. Böylece bu ortamlar öğrencilerin güdülenmelerini ve başarılarını da artırmaktadır (Akkoyunlu ve Yılmaz, 2005; Chou, Hsiao, Shen ve Chen, 2010).

BiT’in bir ürünü olarak çoklu öğrenme ortamlarının hazırlanmasında kuramsal dayanak oluşturabilecek olan "Çoklu Ortam Öğrenme Bilişsel Teorisi'ni" (ÇOÖBT) ortaya koyan Mayer (2001) çoklu ortamı, bir öğretim materyalinin resim ve metinle desteklenerek birden farklı formatta sunulması olarak tanımlamıştır. ÇOÖBT, öğrenmeyi ve öğrenmede kalıcılığı açıklamaya çalışan bir kuramdır (Akkoyunlu ve Yılmaz, 2005; Chou ve diğerleri, 2010). Diğer bir deyişle çOÖBT, insanların öğrenirken bilgiyi nasıl işledikleri ve nasıl öğrendikleri ile ilgilenmektedir (Mayer, 2009). Mayer 2001 yılındaki ÇOÖBT çalışmasında, çoklu ortam tasarımları ile etkili ve kalıcı öğrenmeyi sağlayabilecek 7 ilke ortaya atmıştı (Mayer ve Moreno, 2003). Sonraki yıllarda devam eden çalışmaları ile toplam 100'ün üstünde deney yapan Mayer, çoklu ortam tasarımında izlenecek ilkelerin sayısını 12'ye çıkarmıştır (Mayer, 2009).

Bu ilkeler bilişsel yükün üç türüne göre konu dışı yükü azaltan (extranous load), içsel yükü azaltan (intrinsic load) ve etkili yükü geliştiren (germane load) olmak üzere üç bölüme ayrılmaktadır. Bu ilkelere göre hazırlanan çoklu ortamların öğrenmeyi olumlu yönde etkilediğini doğrulayan birçok çalışma mevcuttur (Mayer, 2009).

\section{Tablo 1. Çoklu Ortam Tasarım ilkeleri}

\begin{tabular}{llll}
\hline Içsel Yükü Azaltan Illkeler & Konu Dışı Yükü Azaltan Illkeler & \multicolumn{2}{l}{ Etkili Yükü Geliştirme İlkeleri } \\
\hline$\bullet \quad$ Bölümlere Ayırma İlkesi & $\bullet$ Tutarlılık & $\bullet$ & Çoklu ortam \\
$\bullet \quad$ Ön-Eğitim & $\bullet$ Dikkat Çekme & $\bullet$ & Kişiselleştirme \\
$\bullet \quad$ Biçim & $\bullet$ Gereksizlik & $\bullet$ & Ses \\
& $\bullet$ Konumsal Yakınlık & $\bullet$ & Resim \\
& $\bullet \quad$ Zamansal Yakınlık & \\
\hline
\end{tabular}

\section{Bölümlere Ayırma İlkesi (Segmenting)}

Bu ilkeye göre karmaşık çoklu ortam dersini, sürekli devam eden bir sunum olarak düzenlemek yerine öğrenenin takip edebileceği biçimde bölümlere ayırmak gerekir (Mayer, 2008). Konuyu bölümlere ayırmanın en klay yolu bir "devam" düğmesi kullanmaktır. Böylece öğrenene kendi hııında öğrenme imkanı verilir (Sorden, 2012)

\section{Ön-Eğitim (pre-training) ilkesi}

Bu ilkeye göre bireyler öğretilecek konuyla ilgili temel kavramları ve bu kavramların özelliklerini bildikleri bir çoklu ortam dersinde daha iyi öğrenirler. Ön-eğitim ilkesi, öğrenenin dersteki ilgili materyali öğrenmeye çalışmasının bilişsel sistemini meşgul etmesi ile ilgilidir (Clark ve Mayer, 2011).

\section{Biçim (Modality) illkesi}

Bu ilkeye göre, öğrenenler, görseller ve yazılardan oluşan çoklu ortam materyaline göre, görseller ve seslerden oluşan çoklu ortam materyali ile daha iyi öğrenirler (Mayer, 2009). Özellikle materyalin karmaşık, tek parça (sürekli akan) ve kullanıcı kontrolünün sınırlı olduğu durumlarda bu ilke kullanıımalıdır (Tabbers, Martens ve Van Merrienboer, 2004).

\section{Tutarlılık (Coherence) ilkesi}

Bu ilkeye göre konu dışı öğeler çoklu ortam tasarımına eklenmediği durumlarda öğrenme daha kolay gerçekleşir (Mayer, 2009). Bu ilke, uygulaması kolay ve öğrenmede güçlü bir etkisi olmasına rağmen çoğunlukla inmal edilir (Clark ve Mayer, 2011). 


\section{Dikkat Çekme (Signaling) ilkesi}

Bu ilkeye göre, önemli çoklu ortam öğeleri vurgulandığında ve çeşitli ipuçları verildiğinde insanlar daha iyi öğrenirler. Dikkat çekme ilkesiyle, öğrenenin çoklu ortam materyalindeki anahtar öğelere odaklanmasını sağlayarak, dışsal bilişsel yükünü azaltmak amaçlanır (Mayer, 2009).

\section{Gereksizlik (Redundancy) illkesi}

Bu ilke Biçim ilkesi ile ilişkilidir. Çoklu ortamlarda genellikle sesli anlatımın yanında metinlere de yer verilmektedir. Ancak video ile anlatılan bir derste görsel ile birlikte verilen sesli anlatımın yanı sıra destekleyici olarak çoklu ortamın metin barındırması gereksizdir. Bir diğer deyişle sesli anlatım varken metinlere yer vermek aşırı bilişsel yüke neden olacaktır.

\section{Uzamsal ve Zamansal Yakınlık ilkesi}

Uzamsal yakınlık ilkesine göre çoklu ortam materyalindeki metinler ve bu metinlerle ilişkili olan görsellerin yakın yerleştirilmesi gerekmektedir. Böylece sözel olmayan kanalın (görsel kanal) yükü azalttlarak öğrenmeye katkı sağlanmış olur (Mayer ve Moreno, 2003). Bir diğer deyişle buradaki amaç uzamsal yakınlık ilkesini çoklu ortamlarda uygulayarak öğrenenlerin dışsal bilişsel yük ile meşguliyetlerini en aza indirmektir.

\section{Çoklu Ortam (Multimedia) ilkesi}

Bu ilkeye göre öğrenenler görsel ve sözel öğelerin bir arada yer aldığı çoklu ortamlarda, sadece sözel veya sadece görsel öğelerin yer aldığı çoklu ortamlara göre daha iyi öğrenirler. Çoklu ortam etkisi olarak da adlandırılır.

\section{Kişiselleştirme (Personalization) ve Ses (Voice) illkesi}

Kişiselleştirme ilkesine göre, öğrenmenin daha iyi gerçekleşmesi için çoklu ortam materyalindeki sözcüklerin resmi bir biçim yerine günlük konuşma diline yakın olması gerekmektedir (Mayer, 2009). Ses ilkesine göre ise bir çoklu ortam sunumunda sözcüklerin mekanik bir ses yerine insan sesi ile seslendirilmesiyle öğrenenler daha iyi öğrenir (Clark ve Mayer, 2011). Böylece öğrenen için doğala yakın bir iletişim ortamı oluşturmak istenir.

\section{Resim (Image) illkesi}

Bu ilkeye göre çoklu ortam materyalinde seslendirmeyi yapan kişinin görüntüsünün yer alması öğrenenlerin daha iyi öğrenmelerini sağlamaz (Mayer, 2009). Aksine gereksiz dışsal yüke neden olur.

ÇOÖBT'ye göre sınıflarda kalıcı öğrenmelerin gerçekleşmesi için çoklu ortamın sunum biçimlerinde çeşitliliğe yönelmek gerekmektedir. Bu nedenle çoklu ortam mesajının birden fazla duyu kanalları kullanılarak aktarılması gerekmektedir. Bunu sağlamak için çoklu ortamın farklı teknolojilerinden (video, ses, animasyon vb.) yararlanılarak, hem görsel hem de işitsel kanallar kullanılmalıdır (Mayer, 2001). Mayer daha çok fen bilimlerindeki disiplinlerde yaptı̆ı araştırmalarda belirli konularda canlandırmaların olduğu eğitsel yazılımlar kullanmış ve gerçekleştirdiği araştırmaların sonucunda çoklu ortamla öğrenmeye yönelik olumlu sonuçlar almıştır (Sezgin, 2009).

BiT kullanılan öğrenme ortamlarında öğrenmenin arttğı ve dolayısıyla öğrencilerin daha başarılı olduğunu gösteren bir çok çalışma vardır(Baş ve Beyhan, 2017; Çetin ve Günay, 2010; Hite, 2005; Koç ve Ayık, 2017; Marbach-Ad, Rotbain ve Stavy, 2008; Özmen, Aküzüm, Sünkür ve Baysal, 2012). Aynı şekilde alanyazında çokluortam yazılımlarının başarıya etkisini inceleyen çeşitli çalışmalar mevcuttur. Issa ve diğerleri (2011), Chang, Tseng ve Tseng (2011), Çetin(2010), Rey ve Steib (2013), Eitel, A., Scheiter, K., \& Schüler, A. (2013), Taşçı ve Soran (2008), Efendioğlu (2012), i̇zmirli (2012), Dinçol Özgür (2011), Sağlıker(2009), Arkün(2007), Yeşiltaş (2010), Yekta (2004) ve Katırcı (2010) çalışmalarında çokluortam yazılımlarının öğrenci başarısına olumlu katkısı olduğu sonucuna varılmıştır. Diğer yandan Altınışık ve Orhan (2002), Ünlü(2009) ve Akbaba(2009) yaptıkları çalışmada çokluortam yazılımlarının öğrenci başarısına katkı sağlamadığı ya da çok az katkı sağladığı belirtilmiştir.

\section{Araştırmanın Amacı}

Araştırmanın amacı ÇOÖBT'ye göre hazırlanan yazılımın öğrenci başarısına (akademik başarı) ve kalıcılığa etkisini incelemektir. Bu doğrultuda araştırmanın problem cümlesi: “Mayer (2009)'in Çoklu Ortam Öğrenme Bilişsel Teorisi ilkelerine dayalı olarak hazırlanan çoklu ortam öğretim yazıııının öğrencilerin akademik başarısına etkisi nedir?" olarak belirlenmiştir.

\section{Araştırmanın problemi}

Araştırmanın genel amacına bağlı olarak çalışma sürecinde aşağıdaki sorulara yanıt aranmıştır. 
Grupların ön-test, son-test ve kalıcılık testlerindeki başarıları arasında,

a) Kullanılan yönteme (ÇOY ile öğretim ve geleneksel yöntem ile öğretim) göre anlamlı bir farklıık var mıdır?

b) Öğrencilerin lisans not ortalamaları (1. sınıf) kontrol edildiğinde kullanılan yönteme göre anlamlı bir fark var midır?

c) Eğitim Bilimlerine Giriş dersinden aldıkları notlar kontrol edildiğinde kullanılan yönteme göre anlamlı bir fark var mıdır?

\section{Yöntem}

Bu çalışmada yarı deneysel desen kullanılmıştır. Çalışmada, ÇOY ve geleneksel yöntemle öğrenen öğrencilerin, Öğretim İlke ve Yöntemleri dersindeki başarıları karşılaştırılmıştır.

Araştırmanın çalışma grubunu BÖTE bölümü, Öğretim İlke ve Yöntemleri Dersini ilk defa alan ikinci sınıf öğrencileri oluşturmuştur. Çalışma grubu bu sınıftaki katılımcı sayısının yeterli olması ve araştırmacının bu bölümdeki öğrencilerle kolay iletişim sağlayabilmesi nedeniyle uygun (convenince) örnekleme yöntemi ile tercih edilmiştir (Balcı, 2009; Büyüköztürk, Kılıç Çakmak, Akgün, Karadeniz ve Demirel, 2013). Araştırmada, deneysel desenlerden öntest-sontest kontrol gruplu yarı deneysel desen kullanılmıştı. Özellikle sosyal bilimlerde yapılan araştırmalarda bu modellerin uygulama geçerliliği yüksektir (Karasar, 2005).

Tablo 2. Araştırma Deseni

\begin{tabular}{cccccc}
\hline Grup & Ön-test & Yöntem & Son-test & Süre & Kalıcılık Testi \\
\hline G1 & O11 & Y1 & O12 & $t$ & O13 \\
G2 & O21 & Y2 & O22 & & O23 \\
\hline \multicolumn{4}{l}{ G1: çOY kullanılan deney grubu, G2: Kontrol grubu } & & \\
Y1: Öğretim Yazılımıyla Yapılan Öğretim, Y2: Geleneksel Öğretim & \\
O11 ve O21 : Ön-test, O12 ve O22: Son-test, O13 ve 023: Kalıcılık Testi &
\end{tabular}

Deney ve kontrol grupları oluşturulurken örneklemde yer alan öğrenciler akademik başarı ve cinsiyet değişkenleri açısından denkleştirilmeye çalışılmıştır. Denkleştirme sonucunda deney grubunda 20 ve kontrol grubunda 21 öğrenci yer almıştir.

Tablo 3. Katılımcıların Cinsiyet ve Lise Türlerine Göre Dağılımları

\begin{tabular}{lcccc}
\hline & \multicolumn{2}{c}{ Cinsiyet } & \multicolumn{2}{c}{ Lise Türü } \\
\cline { 2 - 5 } & $\mathrm{K}$ Iz & Erkek & Meslek Lisesi & Diğer Liseler \\
\hline Deney Grubu & 9 & 11 & 12 & 8 \\
Kontrol Grubu & 13 & 8 & 13 & 8 \\
\hline
\end{tabular}

\section{Uygulama Süreci}

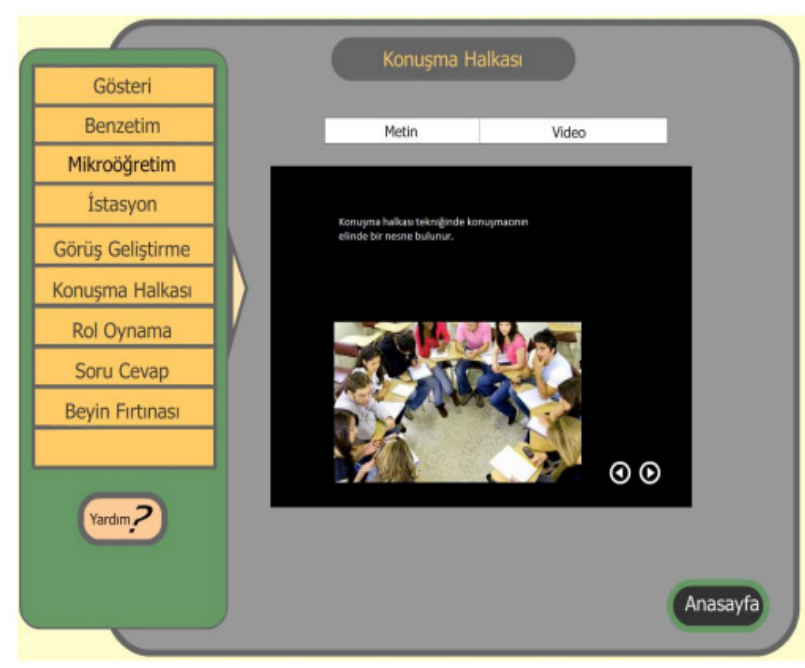

Şekil 1. ÇOY Ekran görüntüsü

Çalışmanın uygulanması sürecinde kontrol grubuna Öğretim Illke ve Yöntemleri Dersi konuları geleneksel yüzyüze 
öğretim gerçekleştirilmiştir. Diğer yandan deney grubunda ise ÇOÖBT’ye göre hazırlanan öğretim yazılımı (Şekil1) kullanılmıştır. Çalışmanın sonunda ön-test ile karşılaştırma yapabilmek amacıyla son-test ve kalıcılık testi uygulanmıştır.

\section{Veri Toplama Araçları}

Araştırmada deneysel işlem öncesi ve sonrasında öğrencilerin Öğretim Illke ve Yöntemleri dersine yönelik başarılarını ve kalıcılık puanlarını ölçmek amacıyla araştırmacı tarafindan geliştirilen başarı testi kullanılmıştı. 39 maddeden oluşan başarı testinin ön uygulamaları sonucunda test ortalaması 19.75, standart sapması 5.69, varyansı 32.47, öğrenciler tarafindan alınan en yüksek puan 30, en düşük puan 7'dir. Testten elde edilen ölçümlerin ortalama güçlük indeksi 0.45 ve güvenirlik düzeyi 0.80 olarak hesaplanmıştı. Bu verilerden hareketle başarı testinin, öğrencilerin Öğretim illke ve Yöntemleri dersine ilişkin akademik başarılarını belirlemede kullanılabilecek bir ölçme aracı olduğu söylenebilir.

\section{Verilerin Analizi}

Araştırmada grupların başarı testi (ön-test, son-test ve kalıcılık testi) ortalama puanlarının normal dağılım gösterip göstermediğini belirlemek amacıyla normallik testlerinden (Shapiro-Wilk) yararlanılmıştr. Ayrıca varyansların homojenliği de Levene testi ile kontrol edilmiştir. Çalışmada yer alan bazı analizlerde anlamlılık düzeyi olarak \%5 ölçütü dikkate alınırken, birden fazla karşılaştırma testi gereken analizlerde ise Bonferroni düzeltmesi yapılarak anlamlılık (p) 0,01 olarak kabul edilmiştir. Verilerin analizi için SPSS 18 paket programı kullanılmıştır.

Deney ve kontrol grubundaki öğrencilerin başarılarının, ön-test, son-test ve kalıcılık testi puanları açısından değerlendirilmesi amacıyla karışık ölçümler için iki faktörlü (yönlü) varyans analizi kullanılmıştır. Karışık ölçümler için iki faktörlü ANOVA, işlem gruplarına bağlı olarak ilişkisiz ölçümlerin ve zamana bağlı olarak tekrarlı ölçümlerin söz edildiği iki faktörlü karışık (split-plot) desenlerde, uygulanan deneysel işlemin etkililiğine ilişkin sattr-sütun ortak etkisini ve satır ile sütun faktörlerinin temel etkilerini test etmek amacıyla kullanılır (Büyüköztürk, 2011).

Literatürde öğrencilerin önceki not ortalamalarının veya başarılarının, daha sonraki başarılarını yordadığını belirten çalışmalar vardır (Kablan, 2010, Şimşek, 2012). Bu nedenle deney ve kontrol grubundaki öğrencilerin ön-test, son-test ve kalıcılık testi puanları ortalamaları, önce lisans not ortalamaları (lisans başarılarının araştırmanın sonucunu etkileyip etkilemediği) ve daha sonra öğrencilerin Eğitim Bilimlerine Giriş dersinden aldıkları notlar (Eğitim Bilimleri dersindeki akademik başarısının araştırma sonucunu etkileyip etkilemediği) kontrol edilerek karşılaştırılmıştır. Bu karşılaştırma işlemi için kovaryans analizi kullanılmıştır. Bir araştırmada etkisi test edilen bir faktörün ya da faktörlerin dışında, bağımlı değişken ile ilişkisi bulunan bir değişkenin ya da değişkenlerin istatistiksel olarak kontrol edilmesini sağlamak için ANCOVA analizi yapılır. Bu bağlamda ANCOVA'nın basit ANOVA'ya göre hata varyansını azaltması ve daha büyük bir istatistiksel güç sağlaması nedeniyle avantaj sağladığı söylenebilir (Büyüköztürk, 2011).

\section{Bulgular}

\section{Deney ve Kontrol Grubunun Başarı Testi Puanları Ortalamalarına Göre Karşılaştırılması}

Bu aşamada deney ve kontrol gruplarının başarı testi ön-test, son-test ve kalıcılık testi ortalama puanları karşılaştrılmıştr(Tablo 4).

Tablo 4. Deney ve Kontrol Gruplarındaki Öğrencilerin Ön-test, Son-test ve Kalıcılık Testi Puanlarına ilişsin Betimsel İstatistikler

\begin{tabular}{lllcc}
\hline \multirow{2}{*}{ Ön-test } & Gruplar & N & $\bar{X}$ & SS \\
& Deney & 20 & 12.20 & 3.38 \\
& Kontrol & 21 & 12.47 & 3.92 \\
\hline \multirow{2}{*}{ Son-test } & Deney & 20 & 25.20 & 4.45 \\
& Kontrol & 21 & 20.00 & 3.61 \\
\hline \multirow{2}{*}{ Kalıcılık Testi } & Deney & 20 & 23.90 & 4.27 \\
& Kontrol & 21 & 17.71 & 3.46 \\
\hline
\end{tabular}

Tablo 4'e göre hem kontrol hem de deney grubu öğrencilerinin başarı ön-test ortalama puanlarına göre son-test başarı puanları ortalama artmıştr. (Kontrol grubu ön-test=12.47, Kontrol grubu son-test=20.00, Kontrol grubu kalıcılık testi=17.71, Deney grubu ön-test=12.2, Deney grubu ön-test=25.2 ve Deney grubu kalıclık testi=23.9). Bu betimsel istatistiklerin çizgi grafiği biçiminde gösterimi Şekil 2'de sunulmuştur. 


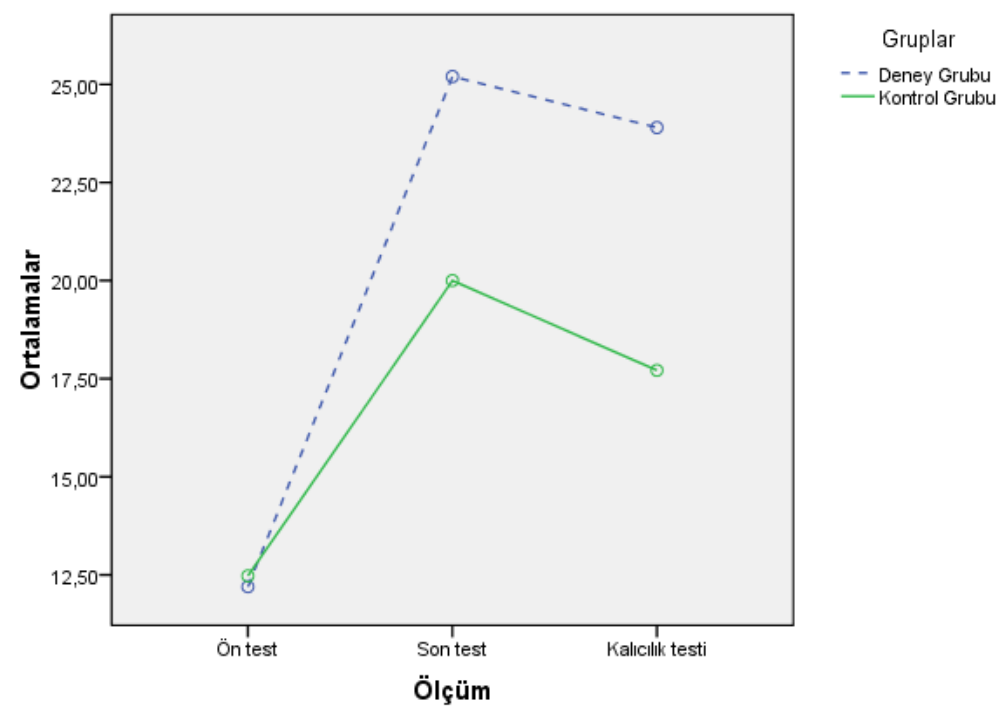

Şekil 2. Deney ve Kontrol Grubu Başarı Testi Ortalamaları (Ön-test, son-test ve kalıcılık testi) Çizgi Grafiği.

Şekil 2'de görüldüğü gibi deney grubu son-test puanlarının, kontrol grubu son-test puanlarına göre daha yüksek olduğu görülmektedir. Ayrıca, son-testten 3 hafta sonra uygulanan kalıcılık testi başarı puanlarına bakıldığında, hem deney grubunda hem de kontrol grubunda son-test başarı puanlarına göre bir azalma gerçekleşmiştir. Ortalamalar arasındaki bu durumun anlamlılığını test etmek için iki yönlü ANOVA testi yapılmıştır(Tablo 5).

Tablo 5. Deney ve Kontrol Grubunun Ön-test, Son-test ve Kalıcılık Testi Puanlarına ilişkin ANOVA Sonuçları

\begin{tabular}{lccccc}
\hline Varyansın Kaynağı & Kareler Toplamı & $\mathrm{Sd}$ & KO & $\mathrm{F}$ & $\mathrm{p}^{*}$ \\
\hline Deneklerarası & 1414.59 & 40 & & & \\
Grup & 421.44 & 1 & 421.44 & 16.55 & $.000^{*}$ \\
Hata & 993.15 & 39 & 25.47 & & \\
Denekleriçi & 3332.78 & 82 & & & \\
Ölçüm (ÖT-ST-KT) & 2461.90 & 2 & 1230.95 & 154.22 & $.000^{*}$ \\
Grup* Ölçüm & 248.30 & 2 & 124.15 & 15.55 & $.000^{*}$ \\
Hata & 622.58 & 78 & 7.99 & & \\
Toplam & 4747.37 & 122 & & & \\
\hline \multicolumn{1}{c}{${ }_{\mathrm{p}<\text { <.01 }}$} & & & & &
\end{tabular}

Tablo 5 incelendiğinde, uygulanan öğretim yöntemine bağlı olarak deney grubu ile kontrol grubunun başarı testi puanları, deney öncesinden sonrasına ve kalıcılık testi sonrasına anlamlı farklıık göstermiştir. Bir diğer deyişle farklı işlem gruplarında olma (deney ve kontrol grubu) ve tekrarlı ölçümler faktörlerinin (ön-test, son-test ve kalıcilık testi), başarı puanları üzerindeki ortak etkilerinin (grup*ölçüm) anlamlı fark oluşturduğu bulunmuştur $(F(2-78)=15.55 ; p<.01)$.

Ancak söz konusu farkın kaynağını belirlemek, diğer bir ifade ile değişkenler arasındaki farklılıkları (hangi testler arasında fark olduğunun incelenmesi) ikişerli gruplar halinde karşılaştırmak için Bonferroni testi sonuçları incelenmiştir (Tablo 6).

Tablo 6. Başarı Testi Puanlarına İlişkin Bonferroni Analizine İlişkin Çoklu Karşılaştırma Sonuçları

\begin{tabular}{clccc}
\hline (I) Ölçüm & (J) Ölçüm & Ortalamaların Farkı(I-J) & SS & $p$ \\
\hline \multirow{2}{*}{ Son-test } & Ön-test & 10,262 & .856 & $.000^{*}$ \\
& Kalıcılık testi & 1,793 & .400 & $.000^{*}$ \\
\hline \multirow{2}{*}{ Kalıcılık testi } & Ön-test & 8,469 & .886 & $.000^{*}$ \\
& Son-test & $-1,793$ & .400 & $.000^{*}$ \\
\hline \multirow{2}{*}{${ }_{p<.01}$} & & & &
\end{tabular}

Karşılaştırma sonuçları, iki grubun başarıları arasında fark olduğunu ve bu farkın istatistiksel açıdan anlamlı olduğunu göstermektedir. Söz konusu anlamlılık, deney ve kontrol gruplarının karşılaştırılan ön-test ile son-test, ön-test ile kalıcılık testi ve son-test ile kalıcılık testleri arasında mevcuttur $(p<.01)$. Bir diğer deyişle çoklu ortama dayalı ve geleneksel öğretime dayalı öğretimin uygulandığı gruplarda, öğrencilerin hem başarılarının ve hem de hatılama düzeylerinin 
deney grubu lehine farklı etkilendiği söylenebilir.

Öğrencilerin Eğitim Bilimlerine Giriş Dersi Notları Kontrol Altına Alındığında Grupların Ön-test, Son-test ve KalıcıIık Testleri Puanlarının Karşılaştırılması

Kontrol grubuna göre deney grubunda belirlenen başarının öğrencilerin Eğitim Bilimlerine Giriş (EBG) Dersi'nden almış oldukları notlar kontrol edildiği durumda da sağlanıp sağlanmadığını test etmek amacıyla ANCOVA analizi yapılmıştr. Diğer bir deyişle deney grubunda elde edilen söz konusu başarıda, eğitim derslerinde zaten başarılı öğrencilerin katkısı olup olmadığını belirlemek amaçlanmıştır. Tablo 7'te ön-test, son-test ve kalıcılık testi puanı düzeltilmiş ortalamalarının gruplara göre betimsel istatistikleri verilmiştir.

Tablo 7. Grupların Ön-test, Son-test ve Kalıcılık Testi Puan Ortalamalarının EBG Notlarına Göre Düzeltilmiş Betimsel İstatistikleri

\begin{tabular}{lccc}
\hline Gruplar & N & Ortalama & Düzeltilmiş Ortalama \\
\hline \multirow{2}{*}{ Deney Grubu } & \multirow{2}{*}{20} & 12.2 & 12.17 \\
& & 25.2 & 25.1 \\
& 23.9 & 23.8 \\
\hline \multirow{2}{*}{ Kontrol Grubu } & 21 & 12.47 & 12.5 \\
& 21 & 20.0 & 20.1 \\
\hline
\end{tabular}

Tablo 7 incelendiğinde, düzeltilmiş ortalama puanlara göre deney grubunda yer alan öğrencilerin ön-test puanının 12.17 , son-test puanının 25.1 ve kalıcılık testi puanının 23.8 olduğu görülmektedir. Kontrol grubunda yer alan öğrencilerin düzeltilmiş ön-test puanı ortalaması 12.5, son-test puan ortalaması 20.1 ve kalııılık testi puan ortalaması ise 17.7 'dir. Diğer bir deyişle öğrencilerin EBG dersinden aldıkları notlar kontrol edildiğinde grupların ön-test, son-test ve kalıcılık testi puanı ortalamaları arasında fark meydana geldiği görülmektedir. Grupların düzeltilmiş ortalama puanları arasında gözlenen farkın anlamlı olup olmadığına ilişkin ANCOVA sonuçları Tablo 8'de verilmiştir.

Tablo 8.Öğrencilerin EBG Dersinden Aldıkları Notlar Kontrol Altına Alındığında Gruplara Göre Karışık Ölçümler İçin íki Faktörlü Ancova Analizi

\begin{tabular}{|c|c|c|c|c|c|}
\hline Varyansın Kaynağı & Kareler Toplamı & sd & Kareler Ortalaması & $\mathrm{F}$ & Anlamlılık Düzeyi (p) \\
\hline EBG Notu (Reg.) & 100.94 & 1 & 100.94 & 5.52 & .000 \\
\hline Grup & 126.40 & 1 & 126.40 & 18.93 & $.000 *$ \\
\hline Hata & 253.66 & 38 & 6.68 & & \\
\hline Toplam & 481 & 40 & & & \\
\hline
\end{tabular}

ANCOVA sonuçlarına göre, farklı gruplarda yer alan öğrencilerin EBG dersinden aldıkları notlara göre düzeltilmiş son-test ortalama puanları arasında anlamlı bir farkın olduğu bulunmuştur $(F(1-38)=18.93 ; p<.01)$. Başka bir deyişle, EBG dersinden aldıkları notlar kontrol altına alındığında ön-test, son-test ve kalıcılık testi puanları çoklu ortamla öğrenme ve geleneksel öğretime göre farklılık göstermektedir.

Lisans Not Ortalamaları Kontrol Altına Alındığında Grupların Ön-test, Son-test ve Kalıcılık Testi Puanlarının Karşılaştırılması Kontrol grubuna göre deney grubunda belirlenen başarının öğrencilerin lisans not ortalamalarının kontrol edildiği durumda da sağlanıp sağlanmadığını test etmek amacıyla ANCOVA analizi yapılmıştır. Bir diğer deyişle, öğrencilerin lisans ortalamalarının (lisans ortalaması yüksek olan öğrencilerin başarısı olup olmadığı) etkisi başarı testi sonuçlarından arındırıldığında gruplar arasında bir farkın olup olmadığı incelenmiştir. Tablo 9'da deney ve kontrol grubuna ait ön-test, son-test ve kalıcılık testi puanları ortalamalarının, lisans not ortalamalarına göre düzeltilmiş betimsel istatistikleri verilmiştir.

Tablo 9. Grupların Başarı Testi Puan Ortalamalarının Öğrencilerin Akademik Ortalamalarına göre Düzeltilmiş Betimsel ỉstatistikleri

\begin{tabular}{lcccc}
\hline Gruplar & $\mathrm{N}$ & Test & Ortalama & Düzeltilmiş Ortalama \\
\hline \multirow{3}{*}{ Deney Grubu } & \multirow{3}{*}{20} & Ön-test & 12.2 & 12.80 \\
& & Son-test & 25.2 & 24.90 \\
& & Kalıcılık testi & 23.9 & 23.8 \\
\hline \multirow{3}{*}{ Kontrol Grubu } & Ön-test & 12.47 & 12.69 \\
& \multirow{2}{*}{21} & Son-test & 20.0 & 19.91 \\
& & Kalıclık testi & 17.71 & 17.01 \\
\hline
\end{tabular}

| Kastamonu Eğitim Dergisi, 27(2), 2019| 
Düzeltilmiş ortalama puanlara göre deney grubunda yer alan öğrencilerin ön-test puanı 12.2, son-test puanı 25.2 ve kalıcılık testi puanı 23.9 olarak belirlenmiştir. Kontrol grubunda yer alan öğrencilerin düzeltilmiş ön-test test puanı ortalaması 12.69, son-test puan ortalaması 19.91 ve kalıcılık testi puan ortalaması ise 17.01'dir. Grupların düzeltilmiş ortalama puanları arasında gözlenen farkın anlamlı olup olmadığına ilişkin karışık ölçümler için iki faktörlü ANCOVA sonuçları Tablo 10 'da verilmiştir.

Tablo 10. Öğrencilerin Lisans Not Ortalamaları Kontrol Altına Alındığında Gruplara Göre Karışık Ölçümler İçin İki Faktörlü Ancova Analizi

\begin{tabular}{lccccc}
\hline Varyansın Kaynağı & Kareler Toplamı & sd & Kareler Ortalaması & F & Anlamlılık Düzeyi (p) \\
\hline Lisans Notu (Reg.) & 112.30 & 1 & 112.30 & 17.61 & .000 \\
Grup & 133.34 & 1 & 133.34 & 20.91 & $.000^{*}$ \\
Hata & 383.34 & 38 & 10.09 & & \\
Toplam & 824.88 & 40 & & & \\
\hline \multicolumn{1}{c}{ p $<.01$} & & & & &
\end{tabular}

ANCOVA sonuçlarına göre, farklı gruplarda yer alan öğrencilerin lisans ortalamalarına göre düzeltilmiş son-test ortalama puanları arasında anlamlı bir farkın olduğu bulunmuştur $(F(1-38)=20.91 ; p<.01)$. Başka bir deyişle, öğrencilerin lisans ortalama notları kontrol altına alındığında son-test puanları çoklu ortamla öğrenme ve geleneksel öğretime göre farklılık göstermektedir.

\section{Sonuçlar}

Bu çalışmada, BÖTE lisans programında yer alan Öğretim Illke ve Yöntemleri dersinde çoklu ortam ilkelerine uygun olarak geliştirilmiş öğretim yazılımının (ÇOY), öğrencilerin başarısına etkisini belirlemek amaçlanmıştır. Bu doğrultuda deney grubunda ÇOY ile öğretim yapılmış kontrol grubunda ise geleneksel öğretim yapılmıştır. Elde edilen veriler karışık ölçümler için iki yönlü ANOVA ve ANCOVA analizleri yapılarak değerlendirilmiştir. Hem deney ve hem de kontrol grubunun ön-test ile son-test puanları arasında ve kontrol grubunun ön-test ve son-test puanları arasında anlamlı fark bulunmuştur. Bu nedenle her iki gruba uygulanan yöntemlerin öğrenmede etkili olduğu söylenebilir. Ancak grupların son-test ortalama puanlarına bakıldığında deney grubu ortalama puanlarının daha yüksek olduğu, dolayısıyla çoklu ortamla işlenen dersin öğrencilerin başarısına etkisinin daha fazla olduğu söylenebilir. Bu sonuç, alanyazında çoklu ortam uygulamalarının etkiliğinin araştııldığı Issa ve diğerleri (2011), Chang, Tseng ve Tseng (2011), Çetin(2010), Han ve diğerleri (2013), Rey ve Steib (2013), Eitel ve diğerleri (2013), Taşçı ve Soran (2008), Efendioğlu (2012), i̇zmirli (2012), Dinçol Özgür (2011), Sağlıker(2009), Arkün(2007), Yeşiltaş (2010), Yekta (2004) ve Katırcı (2010) çalışmalarının sonuçlarıyla örtüşmekteyken, Altınışık ve Orhan (2002), Ünlü(2009) ve Akbaba(2009) çalışmalarıyla örtüşmemektedir.

Deney grubuna ait son-test ile kalıcılık testi ortalama puanları arasında ve kontrol grubuna ait son-test ve kalıcılık testi ortalamalarında bir miktar azalma gerçekleşmiştir. Ancak ortalamalardaki bu azalmanın miktarı, kontrol grubu puanlarında daha fazla görülmüştür. Yapılan analizlerde deney grubu son-test ve kalıcılık testi ortalama puanları arasında istatistiksel olarak anlamlı fark bulunmamıştr. Ancak kontrol grubu son-test ve kalıclık testi ortalama puanlarına göre anlamlı fark bulunmuştur. Bu sonuçlara göre, deney grubu öğrencilerinin hatıllama düzeyleri kontrol grubu öğrencilerine göre daha fazla olduğu belirlenmiştir. Diğer bir deyişle çoklu ortamla öğrenen öğrencilerin geleneksel olarak öğrenen öğrencilere göre bilgilerin kalıcılığı açısından daha başarılı olduğu söylenebilir. Bu sonuca paralel olarak Dinçol Özgür (2011), Sezgin (2002, 2009) , Issa ve diğerleri (2011), Eitel ve diğerleri (2013), Mautone ve Mayer (2001), Mayer (2001, 2009), Mayer ve Anderson (1992), Raupers (2000), Menne ve Menne (1972; Akt: Akkoyunlu ve Yilmaz, 2005) Mayer ve Moreno (1998), Moreno ve Mayer (1999b), Mayer ve Moreno (2003) çalışmalarında çoklu ortamın, öğrencilerin hatırlama düzeylerine olumlu etkisinin olduğunu belirtmişlerdir.

Çalışmada yer alan öğrencilerin lisans not ortalamaları ve EBG dersinden aldıkları notların ön-test, son-test ve kalıcılık testi puanlarındaki etkisi arındırıldığında gruplar arasında anlamlı farkın olup olmadığı incelenmiştir. Buna göre deney grubunda yer alan öğrencilerin hem son-test hem de kalıclık testi düzeltilmiş ortalama puanlarına göre kontrol grubunda yer alan öğrencilerden daha başarılı olduğu belirlenmiştir. Bir diğer deyişle, araştırmada belirlenen çoklu ortamla öğrenmenin başarıya olumlu etkisinin, sadece EBG dersi notu yüksek olan öğrencilerin değil, deney grubundaki bütün öğrencilerin ortak başarısı olduğu sonucuna varılmıştır.

\section{5. Öneriler}

Çalışmada deney grubu öğrenenlerinin kontrol grubu öğrenenlerine oranla öğrenmede ve kalıcılıkta daha başarılı olması çoklu ortam yazılımının ÇOÖBT’ye göre hazırlanmasına dayandırılabilir. 
Bu sonuçlar doğrultusunda aşağıdaki öneriler yapılabilir:

- Başka derslerdeki (diğer Eğitim Bilimleri dersleri vb.) konuların öğretimi için de bu tarz öğretim yazılımları geliştirilebilir. Böylece bu yazılımların akademik başarıya etkisi araştırılabilir.

- Öğretim yazılımı hazırlarken ÇOÖBT gibi kuramsal temellere dikkat edilmelidir.

- Yapılabilecek diğer çalışmalarda ÇOÖBT Tasarım İlkelerinin her birinin ayrı ayrı etkisinin araştrıldığı özel araştırmalar da yapılabilir.

\section{Kaynakça}

Akkoyunlu, B. ve Yılmaz, M. (2005). Türetimci çoklu ortam öğrenme kuramı. Hacettepe Üniversitesi Eğitim Fakültesi Dergisi, 28, 9-18.

Baş, G. ve Beyhan, Ö. (2017). Sosyal-yapılandırmacı öğrenme ortamı tasarımının öğrenenlerin akademik başarılarına ve derse yönelik tutumlarına etkisi. Mehmet Akif Ersoy Üniversitesi Eğitim Fakültesi Dergisi, 1(41), 137. http://doi.org/10.21764/efd.35974

Chou, C. M., Hsiao, C. H., Shen, H. C. ve Chen, S. G. (2010). Analysis of factors in technological and vocational school teachers' perceived organizational innovative climate and continuous use of e-teaching: Using computer self-efficacy as an intervening variable. The Turkish Online Journal of Educational Technology, 9(4), 35-48.

Clark, R. E. ve Mayer, R. C. (2011). Proven Guidelines for Consumers and Designers of Multimedia Learning (3rd ed.). San Francisco: Pfeiffer.

Çetin, O. ve Günay, Y. (2010). Fen eğitiminde web tabanlı öğretimin öğrencilerin akademik başarılarına ve tutumlarına etkisi. Çukurova Üniversitesi Eğitim Fakültesi Dergisi, 3(38), 19-34.

Eitel, A., Scheiter, K., \& Schüler, A. (2013). How inspecting a picture affects processing of text in multimedia learning. Applied Cognitive Psychology, 27, 451-461. https://dx.doi.org/10.1002/acp.2922.

Hite, A. S. (2005). Are we there yet? A study of K-12 teachers' efforts at technology integration. The University of Pennsylvania, United States-Pennsylvania.

Hussain, D. (2018). The Development of ICT tools for e-inclusion qualities BT - online engineering ve internet of things. In M. E. Auer ve D. G. Zutin (Eds.), (pp. 645-651). Cham: Springer International Publishing.

Issa, N., Schuller, M., Santacaterina, S., Shapiro, M., Wang, E., Mayer, R., \& DaRosa, D. (2011). Applying multimedia design principles enhances learning in medical education, Medical Education, 45 (8), 818-826 DOI: 10.1111/j.1365-2923.2011.03988.xKoç, A. ve Ayık, Y. Z. (2017). Sosyal medya destekli eğitim: 6. ve 7. sınıf fen bilimleri ve ingilizce derslerinde sosyal ağ kullanımının öğrencilerin akademik başarılarına etkisi. European Journal of Science and Technology, 6(10), 7-19.

Karasar N. (2005). Bilimsel Araşttrma Yöntemi. Ankara: Nobel Yay. 14. Baskı.

Marbach-Ad, G., Rotbain, Y. ve Stavy, R. (2008). Using computer animation and illustration activities to improve high school students' achievement in molecular genetics. Journal of Research in Science Teaching, 45(3), 273-292. http://doi.org/10.1002/tea.20222

Mayer, R. E., Moreno, R. (2003). Nine ways to reduce cognitive load in multimedia learning. Educational Psychologist, 38(1), 43-52.

Mayer, R. E. (2001). Multimedia Learning. New York: Cambridge University Press.

Mayer, R. E. (2008). Applying the science of learning: Evidence-based principles for the design of multimedia instruction. American Psychologist, 63(8), 760-769.

Mayer, R. E. (2009). Multimedia learning (2nd ed.). New York: Cambridge University Press.

Nalçacı, A. ve Ercoşkun, M. H. (2005). Illköğretim sosyal bilgiler derslerinde kullanilan materyaller. Kazım Karabekir EKilim Fakültesi Dergisi, 11.

Rey, G.D. \& Steib, N. (2013). The personalization effect in multimedia learning: The influence of dialect. Computers in Human Behavior, 29, 2022-2028

Özmen, F., Aküzüm, C., Sünkür, M. ve Baysal, N. (2012). Sosyal ağ sitelerinin eğitsel ortamlardaki işlevselliği. NWSA: Education Sciences, 7(2), 496-506. Retrieved from http://dergipark.ulakbim.gov.tr/nwsaedu/article/view/5000063084

Sorden, S. D. (2012). The cognitive theory of multimedia learning. Handbook of educational theories. Charlotte, NC: Information Age Publishing.

Saban, A. (2008). Öğretim teknolojisi ve materyal tasarımı ile ilgili temel kavramlar. (K. Selvi, Ed.). Ankara: Anı Yayınclık.

Semerci, A. (2006). illköğretim birinci kademede görev yapan sınıf öğretmenlerinin, etkili materyal kullanma yeterlilikleri üzerine öğretmen ve yönetici görüşleri (Yayınlanmamış yüksek lisans tezi), Fırat University.

Sezgin, M. E. (2009). Çok ortamlı̈ ŏgrenmede bilişsel kuram ilkelerine göre hazırlanan öğretim yazılımının bilişsel yüke, öğrenme düzeylerine ve kalıcılığa etkisi (Yayınlanmamış doktora tezi), Çukuroava Üniversitesi, Adana.

Tabbers, H. K., Martens, R. L. ve Van Merrienboer, J. J. G. (2004). Multimedia instructions and cognitive load theory: Effects of modality and cueing. British Journal of Educational Psychology, 74, 71-81.

Taşkesen, S. ve Yılmaz, M. (2018). 3D modelleme programları ve figür imajlarının desen dersi başarılarına etkisi. Kastamonu Üniversitesi Kastamonu Eğitim Dergisi, 26, 1-18. http://doi.org/10.24106/kefdergi.350183

Tezci, E. (2016). Öğretmenlerin BiT entegrasyon yaklaşımlarının ölçülmesine yönelik ölçek geliştirme. Kastamonu Eğitim Dergisi, 24(2), 975-992.

Yılmaz, A. ve Özgür Dinçol, S. (2012). Türetimci çoklu ortamın öğretmen adaylarının öğrenme stillerine göre başarı, tutum ve kalıcllı̆a etkisi. Hacettepe Üniversitesi Eğitim Fakültesi Dergisi (H. U. Journal of Education), 41, 441-452. 